\title{
Implementasi Raspberry Pi 3 Sebagai Wireless Access Point Pada STIPER Sriwigama Palembang
}

\author{
Rahmat Novrianda Dasmen ${ }^{1 *}$ \\ ${ }^{1}$ Program Studi Teknik Komputer, Fakultas Vokasi, Universitas Bina Darma, Palembang \\ ${ }^{1}$ Jln. Jendral A. Yani No. 03, Kota Palembang, 30264, Indonesia \\ email: ${ }^{1}$ rahmat.novrianda.d@mail.com
}

Received: 17 Juni 2018; Revised: 1 Oktober 2018; Accepted: 20 Oktober 2018

Copyright @2018, Politeknik Harapan Bersama, Tegal

\begin{abstract}
STIPER Sriwigama Palembang is one of the agricultural science college located in Palembang City. STIPER Sriwigama Palembang has a computer network that utilizes wireless transmission media. Therefore, one of the most needed devices is AP (Access Point). Currently, STIPER Sriwigama Palembang only has 2 Access Point so that the internet network can not be spread to the entire environment of STIPER Sriwigama Palembang. With these problems, in this research will be designed WAP (Wireless Access Point) by utilizing Raspberry Pi 3 Model B owned by STIPER Sriwigama Palembang. Raspberry Pi 3 Model B is a mini computer that is about the size of a credit card equipped with SD card which is where the installation of Operating System and data storage managed on Raspberry Pi 3. Building a Wireless Access Point can be done by doing some configuration stages to Raspberry $\mathbf{P i}$ 3 Model B which has been installed by Raspbian Operating System. With the construction of WAP utilize Raspberry Pi 3 , then the internet network will be spread throughout the environment of STIPER Sriwigama Palembang by using wireless transmission media.
\end{abstract}

Abstrak - STIPER Sriwigama Palembang yang merupakan salah satu sekolah tinggi ilmu pertanian yang berada di Kota Palembang. STIPER Sriwigama Palembang telah memiliki jaringan komputer yang memanfaatkan media transmisi wireless. Oleh sebab itu, salah satu perangkat yang paling dibutuhkan adalah AP (Access Point). Saat ini, STIPER Sriwigama Palembang hanya memiliki 2 Access Point sehingga jaringan internet belum dapat tersebar ke seluruh lingkungan STIPER Sriwigama Palembang. Dengan permasalahan tersebut, pada penelitian ini akan dirancang WAP (Wireless Access Point) dengan memanfaatkan perangkat Raspberry Pi 3 Model B yang dimiliki STIPER Sriwigama Palembang. Raspberry Pi 3 Model B merupakan mini komputer yang berbentuk seukuran kartu kredit yang dilengkapi dengan SD card yang merupakan tempat instalasi Sistem Operasi dan penyimpanan data yang dikelola pada Raspberry Pi 3. Membangun suatu Wireless Access Point dapat dilakukan dengan melakukan beberapa tahapan konfigurasi terhadap Raspberry Pi 3 Model B yang telah terpasangkan Sistem Operasi Raspbian. Dengan dibangunnya WAP memanfaatkan Raspberry Pi 3, maka jaringan internet akan tersebar keseluruh lingkungan STIPER Sriwigama Palembang dengan menggunakan media transmisi wireless.

Kata Kunci - Access Point, Internet, Wireless Access Point, Raspberry Pi 3, Raspbian.

*) Corresponding Author: (Rahmat Novrianda D)

Email: rahmat.novrianda.d@gmail.com

\section{PENDAHULUAN}

STIPER (Sekolah Tinggi Ilmu Pertanian) Sriwigama Palembang adalah salah satu sekolah tinggi bidan ilmu pertanian yang terletak di Kota Palembang. Sebagai salah satu institusi yang bergerak di bidang pendidikan saat ini sangat diperlukan jaringan komputer yang terkoneksi dengan internet. Pada STIPER Sriwigama Palembang, koneksi internet disebarkan dengan memanfaatkan jaringan wireless. Jaringan wireless merupakan teknologi jaringan komputer tanpa kabel, yaitu menggunakan gelombang berfrekuensi tinggi sehingga komputer-komputer itu bisa saling terhubung tanpa menggunakan kabel [1]. Pada penelitian sebelumnya, penulis telah membangun keamanan jaringan wireless pada STIPER Sriwigama dengan menggunakan Radius Server, dimana dijelaskan bahwa rancangan untuk penyebaran jaringan internet pada lingkungan STIPER Sriwigama Palembang membutuhkan 5 AP (Access Point) [2]. AP (Access Point) adalah sebuah perangkat jaringan yang berisi sebuah transceiver dan antena untuk transmisi dan menerima sinyal ke dan dari clients remote. AP berfungsi sebagai pengatur lalu lintas data, sehingga memungkinkan banyak client dapat saling terhubung melalui jaringan (Network) [3]. Pada saat ini, di lingkungan STIPER Sriwigama Palembang hanya memiliki 2 AP dan masih kurang 3 AP lagi untuk melengkapi kebutuhan penyebaran jaringan internet secara menyeluruh pada lingkungan STIPER Sriwigama Palembang.

Dengan adanya permasalahan di atas, maka pada penelitian ini bertujuan untuk melengkapi kekurangan AP tersebut dengan cara membangun AP memanfaatkan perangkat keras yang dimiliki oleh STIPER Sriwigama Palembang. Dalam hal ini, staf STIPER Sriwigama Palembang memiliki beberapa Raspberry Pi 3 Model B yang telah diperbolehan untuk dimanfaatkan dalam melengkapi perangkat jaringan wireless yang dibangun pada STIPER Sriwigama Palembang. Raspberry Pi 3 Model B merupakan salah satu mini komputer yang dikembangkan oleh Raspberry Pi Foundation [4]. Raspberry Pi merupakan komputer mungil seukuran dengan sebuah kartu kredit dengan berbagai fungsi yang dapat dilakukannya. Raspberry Pi menggunakan Sistem Operasi Raspbian [5]. Raspberry Pi memiliki prosesor dengan spesifikasi $700 \mathrm{MHz}$ ARM11 serta pada Raspberry Pi Model B memiliki RAM sebesar $512 \mathrm{MB}$, SD card sebagai media penyimpanannya, 2 port USB, konektor HDMI serta port 
ethernet [6]. Pada penelitian ini, peneliti merancang Raspberry Pi 3 yang telah di-install sistem operasi Raspbian menjadi WAP (Wireless Access Point) dengan melakukan beberapa konfigurasi yang dibutuhkan. WAP digunakan untuk menghasilkan jaringan WLAN (Wireless Local Area Network) atau juga untuk memperbesar jumlah ruang lingkup jaringan wifi yang telah ada [7].

\section{PENELITIAN YANG TERKAIT}

Penelitian terdahulu yang telah dilakukan oleh penelitipeneliti sebelumnya adalah dalam hal pemanfaatan perangkat access point, baik access point biasa maupun wireless access point. Berikut ini penelitian-penelitian sebelumnya yang membahas tentang perancangan dan penggunaan perangkat WAP yang membutuhkan modal relatif tinggi, yaitu: rancang bangun keamanan jaringan wireless pada STIPER Sriwigama Palembang dengan Radius Server [2], Impementasi Pull Message dengan menggunakan Restful Web Service pada komunikasi Wireless Sensor [7], Rancang bangun sistem Hotspot manggunakan Captive Portal [8], Analisa Kerja Access Point Jaringan Wireless pada Universitas Al Asyariah Mandar [9]. Penelitian - penelitian tersebut menjelaskan bahwa peneliti menggunakan Raspberry dan Wireless Access Point sebagai 2 (dua) hardware utama yang dibutuhkan. Oleh karena itu, pada penelitian ini akan memberikan solusi untuk membangun Wireless Access Point menggunakan Raspberry, sehingga peneliti selanjutnya cukup membutuhkan Raspberry sebagai hardware utama yang multi fungsi serta menggunakan modal yang lebih hemat dibandingkan membeli perangkat WAP saja.

Selain itu, pada penelitian ini juga dibutuhkan referensireferensi dari peneliti sebelumnya tentang pemanfaatan serta cara kerja dari Raspberry Pi sehingga dalam pelaksanaan penelitian ini dapat diselesaikan dengan baik serta dengan penelitian ini juga akan menambah daftar kegunaan perangkat Raspberry Pi yang dapat diterapkan. Berikut ini penelitianpenelitian sebelumnya yang terkait : Automatisasi Smart Home dengan Raspberry Pi dan Smartphone Android [10], Pemanfaatan Raspberry Pi dan Perangkat Lunak Bebas Terbuka (FOSS) pada Pendidikan Dasar untuk mengatasi Kesenjangan Digital [11], penerapan sistem informasi smart classroom berbasis Internet Of Things dengan Raspberry Pi di Jurusan Teknik Informatika Universitas Negeri Surabaya [12], Implementasi Raspberry Pi sebagai IP Kamera untuk memonitoring studio bioskop [13]. Beberapa penelitian terdahulu di atas memberikan kajian tentang implementasi maupun pemanfaatan Raspberry Pi untuk berbagai teknologi yang dibutuhkan. Pada penelitian ini, dihasilkan juga bahwa perangkat Raspberry $\mathrm{Pi}$ dapat dimanfaatkan untuk pengembangan teknologi yaitu WAP (Wireless Access Point).

\section{METODE PENELITIAN}

\section{A. Metode Action Research}

Metode penelitian yang digunakan pada penelitian saat ini ialah metode Action Research dimana pada metode action research, dideskripsikan, diinterpretasi dan dijelaskan suatu situasi pada waktu yang bersamaan guna melakukan perubahan ataupun intervensi dengan tujuan perbaikan serta partisipasi [14]. Berikut penjelasan tentang metode action research yang digunakan pada penelitian saat ini, seperti ditunjukn pada Gbr.1.

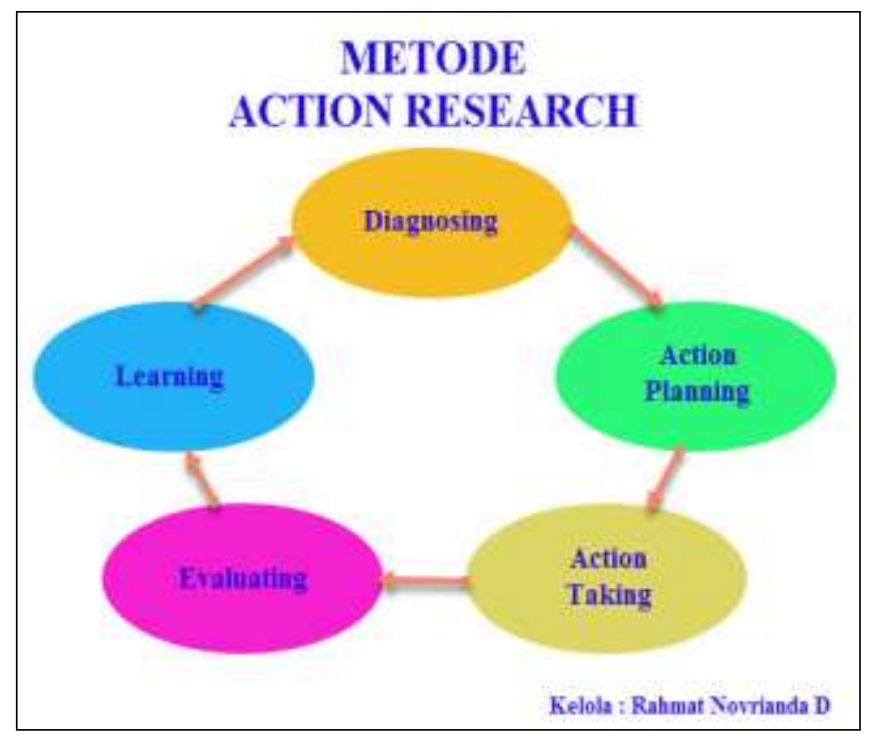

Gbr. 1 Metode Action Research

Berdasarkan pada Gbr.1 beberapa tahapan dialkukan, dianataranya adalah:

- Diagnosing: Pada tahapan ini, dilakukan pemantauan tentang kebutuhan WAP (Wireless Access Point) pada STIPER Sriwigama Palembang.

- Action planning: Mengelola suatu perencanaan yang dapat dipergunakan dalam memecahkan permasalahan kebutuhan pada STIPER Sriwigama dengan memanfaatkan perangkat Raspberry Pi yang ada.

- Action taking: Pengambilan tindakan terhadap perangkat yang dimiliki STIPER Sriwigama Palembang, yaitu Raspberry Pi untuk dikonfigurasikan sehingga dapat dimanfaatkan menjadi WAP (Wireless Access Point).

- Evaluating: Setelah dilakukan konfigurasi terhadap Raspberry Pi, maka dievaluasi fungsi dari Raspberry tersebut sudah sesuai atau belum untuk menjadi suatu WAP (Wireless Access Point).

- Learning: Jika Raspberry Pi telah sesuai dengan WAP (Wireless Access Point) yang dibutuhkan, maka dilakukan pembelajaran tentang penggunaan, pemeliharaan hingga pengembangan WAP terhadap jaringan komputer STIPER Sriwigama Palembang.

\section{HASIL DAN PEMBAHASAN}

Raspberry Pi dapat melakukan banyak hal seperti pada sebuah komputer desktop, seperti mengedit dokumen, memutar video HD, bermain game, coding. Raspberry $\mathrm{Pi}$ tidak memiliki kekuatan atau spesifikasi seperti dekstop PC tapi karena harganya yang jauh lebih murah maka kita bisa memodifikasi tanpa memikirkan harga.

Raspberry Pi juga bagus dalam melakukan banyak hal yang tidak membutuhkan komputer mahal untuk membuatnya seperti berfungsi sebagai NAS (Network Attached Storage), web server, router, media center, torrent box, hingga menjadi WAP (Wireless Access Point). WAP secara khusus diatur 
simpul - simpul di jaringan WLAN (Wireless Lokal Area Network). Berikut ini adalah tahapan dalam implementasi Raspberry Pi menjadi suatu WAP (Wireless Access Point), diantaranya yaitu:

1) Perangkat Raspberry $\mathrm{Pi}$ yang merupakan mini computer juga memerlukan Sistem Operasi untuk menjalankan proses perintahnya, maka pada penelitian ini digunakan Sistem Operasi Raspbian pada Raspberry Pi.

2) Berikut ini adalah proses agar peneliti dapat mengetahui IP address dan netmask yang terkonfigurasi pada Raspberry Pi yang akan digunakan.

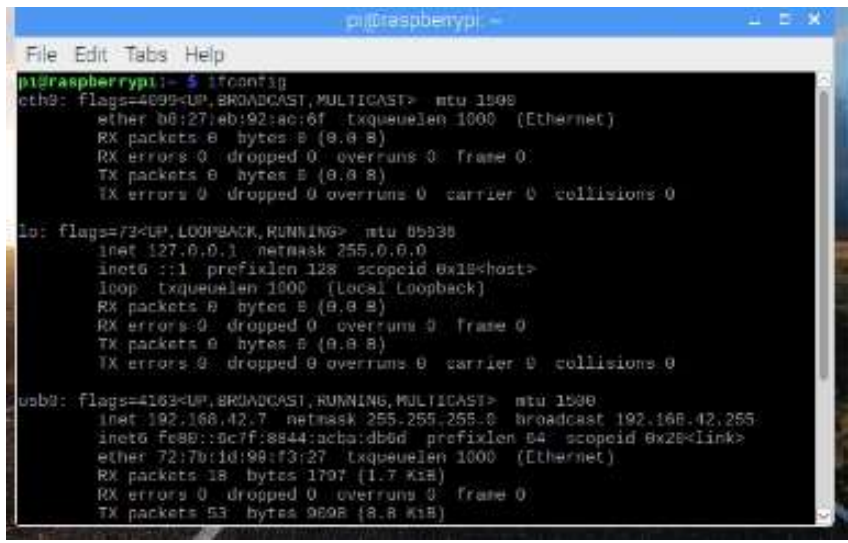

Gbr. 2 Menjalankan perintah ifconfig

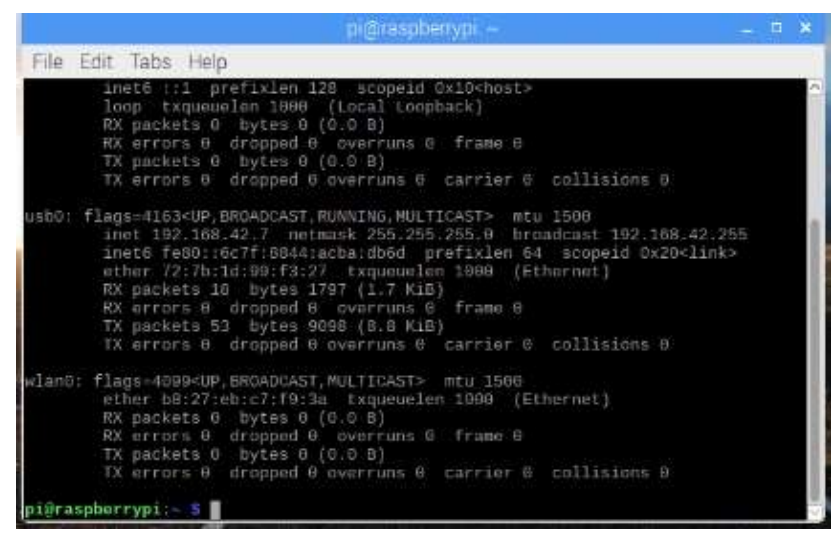

Gbr. 3 Tampilan IP address dan netmask Raspberry Pi

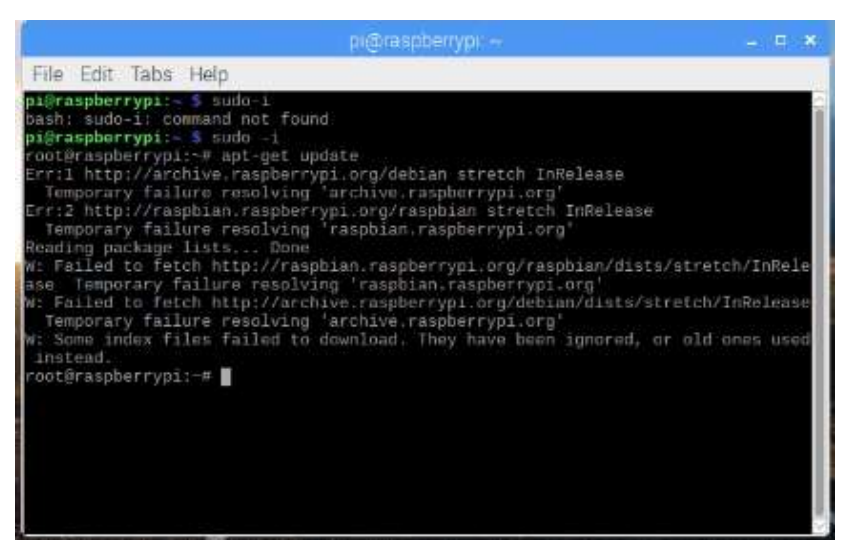

Gbr. 4 Perintah untuk update Raspberry Pi
3) Sebelum dilakukan konfigurasi lebih lanjut, maka diperlukan proses update pada Raspberry $\mathrm{Pi}$ untuk memperbaiki serta menambahkan fitur-fitur yang terbaru untuk Raspberry Pi.

4) Agar dapat mengembangkan Raspberry Pi menjadi Wireless Router atau Wireless Access Point maka perlu dilakukan install paket hostapd pada Raspberry Pi tersebut. Selain itu, Raspberry Pi juga perlu dilakukan install paket dnsmasq yang berguna untuk menjadikan Raspberry sebagai DHCP dan DNS server. Berikut ini adalah proses instalasi kedua paket tersebut pada Raspberry Pi yang telah dilakukan pada penelitian ini.

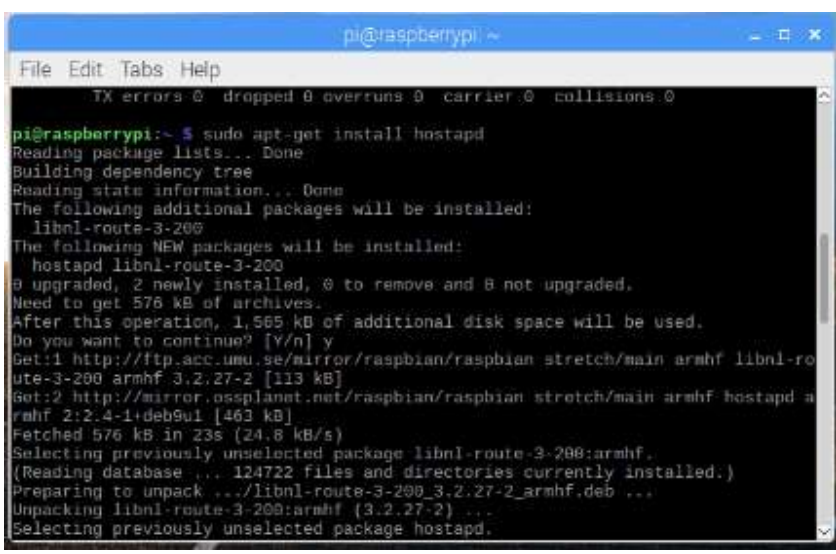

Gbr. 5 Proses install paket hostapd

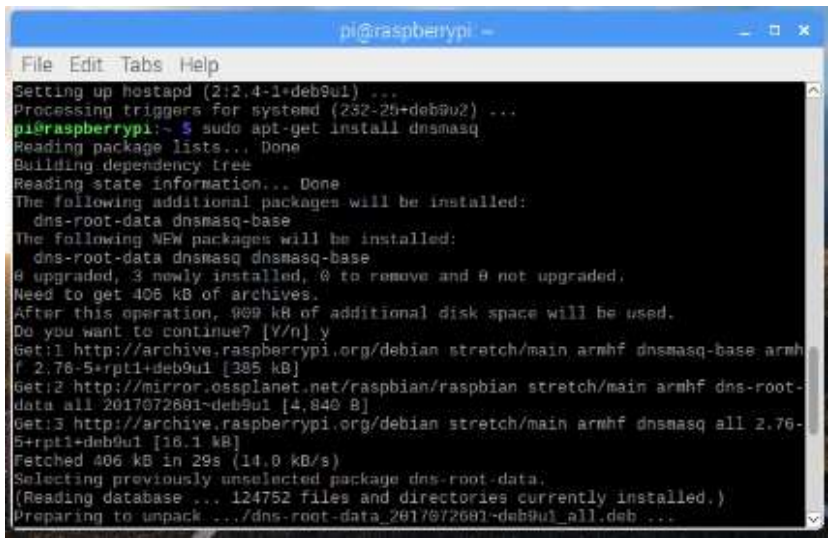

Gbr. 6 Proses install paket dnsmasq

5) Sebelum melanjutkan konfigurasi WAP, maka perlu dilakukan penghentian paket hostapd seperti pada Gbr.7 sehingga tidak terjadi autorun selama proses konfigurasi WAP dilakukan. 


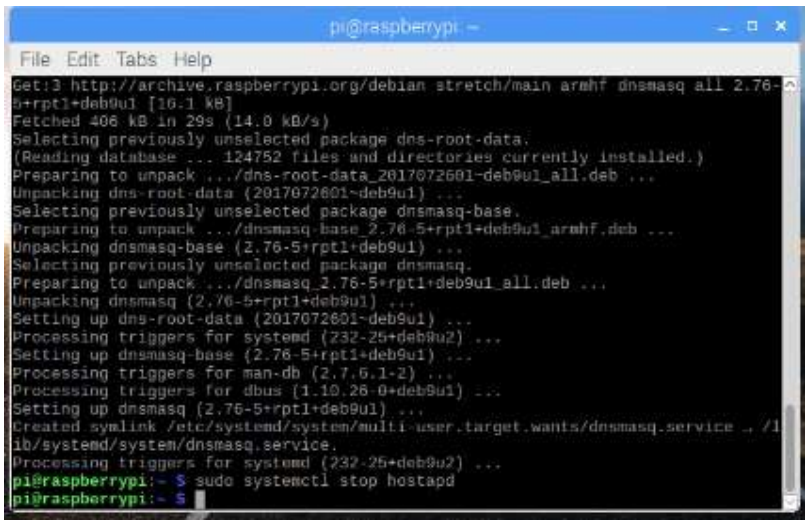

Gbr. 7 Proses menghentikan paket hostapd

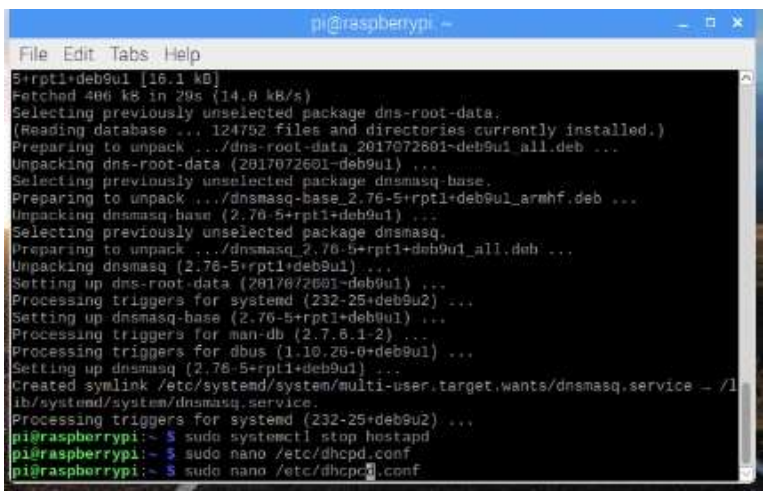

Gbr. 8 Melakukan konfigurasi $d h c p$

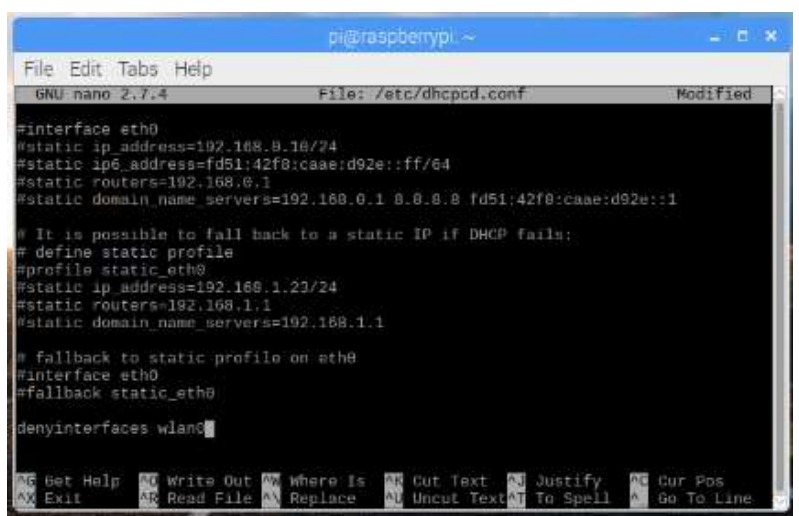

Gbr. 9 Menambahkan isi dari file dhcpcd.conf

6) Agar user yang terhubung pada Raspberry Pi yang telah menjadi WAP memperoleh IP address secara otomatis, maka perlu dilakukan konfigurasi DHCP pada Raspberry Pi, seperti pada Gbr.8 dan Gbr.9.

7) Berikut ini hasil dari konfigurasi network interface pada Raspberry Pi serta pengisian IP address sesuai dengan kebutuhan penelitian ini seperti di bawah ini:

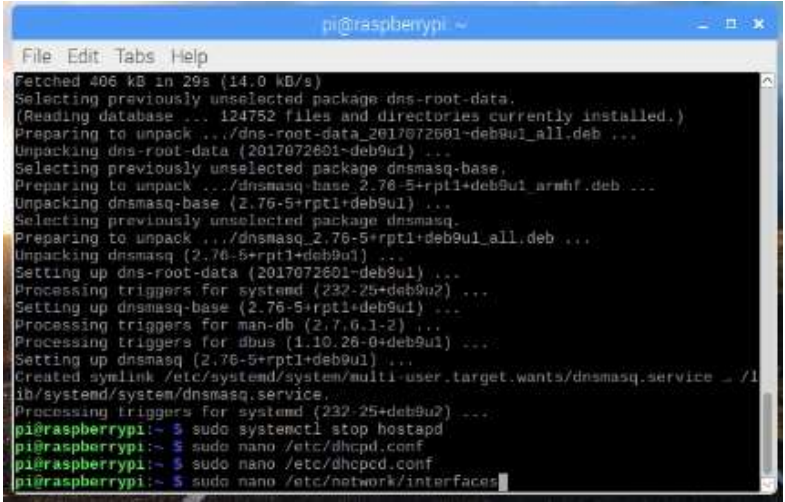

Gbr. 10 Melakukan konfigurasi network interfaces

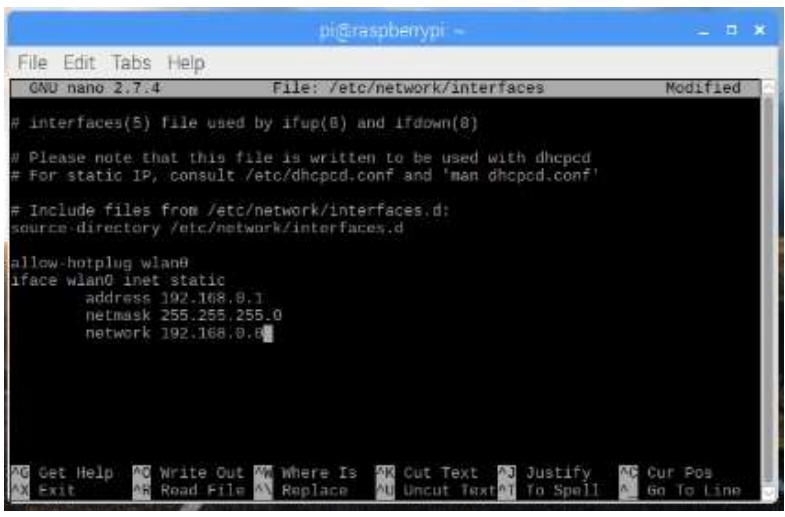

Gbr. 11 Melakukan pengisian IP address

8) Berikut ini merupakan hasil penelitian dalam melakukan konfigurasi terhadap paket dnsmasq dan paket hostapd sehingga Raspberry Pi dapat dipergunakan menjadi WAP (Wireless Access Point), seperti Gbr.12.

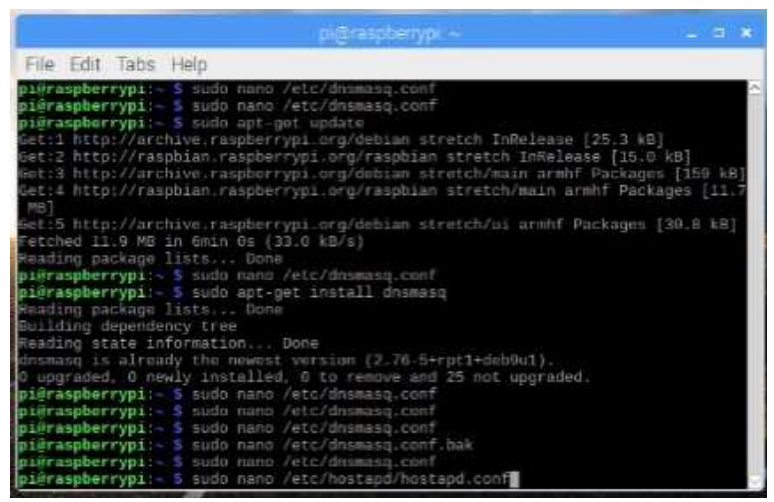

Gbr. 12 Perintah sudo nano /etc/dnsmasq.conf 


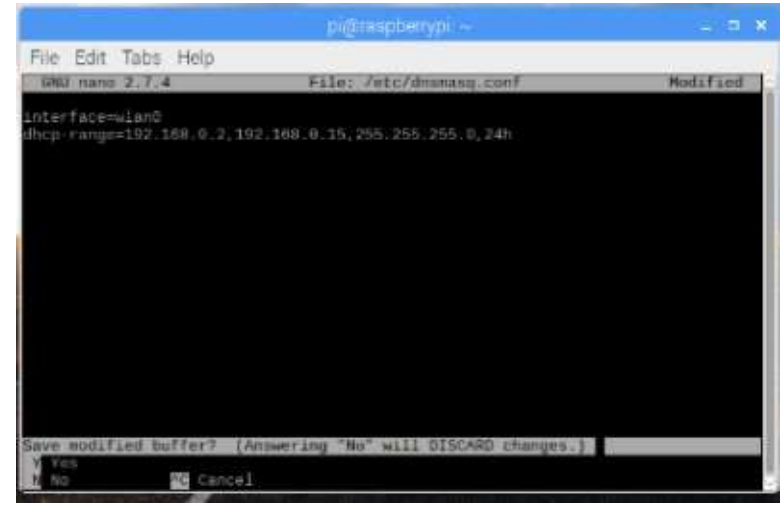

Gbr. 13 Melakukan konfigurasi isi file dnsmasq.conf

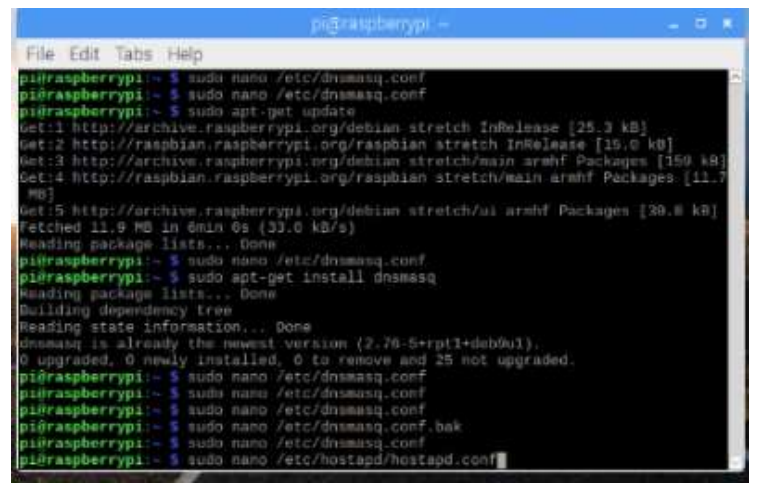

Gbr. 14 Perintah sudo nano /etc//hostapd/hostapd.conf

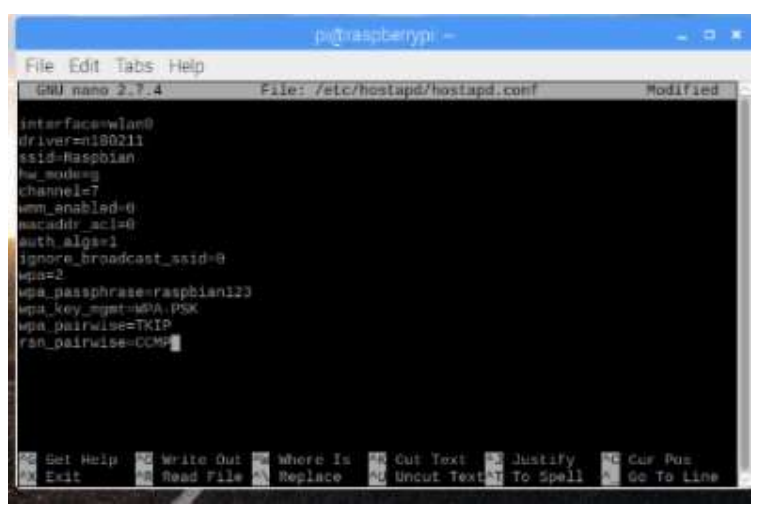

Gbr. 15 Konfigurasi isi file hostapd.conf

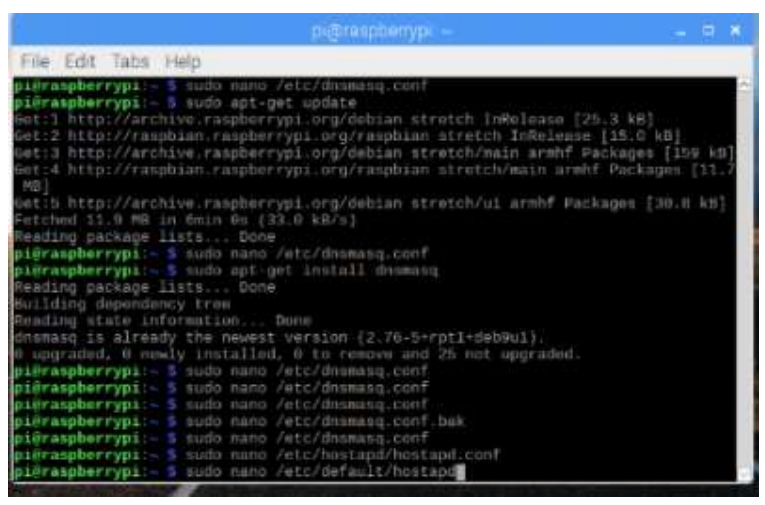

Gbr. 16 Perintah sudo nano /etc/default/hostapd

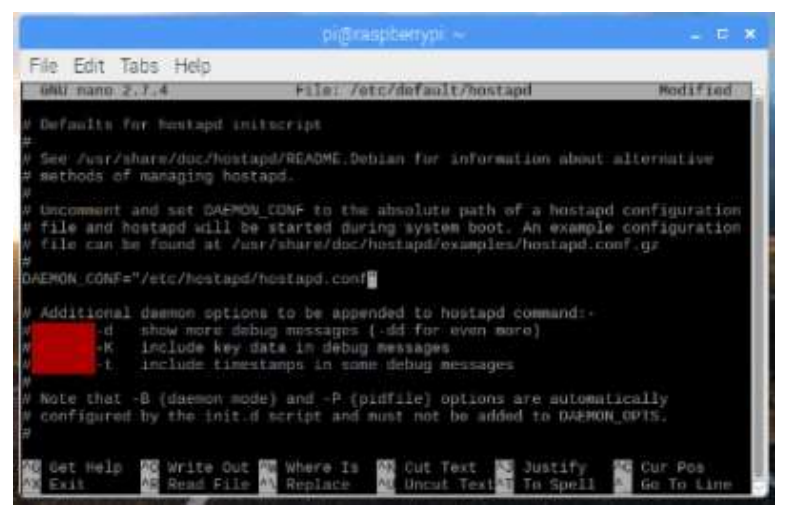

Gbr. 17 Konfigurasi isi file default hostapd

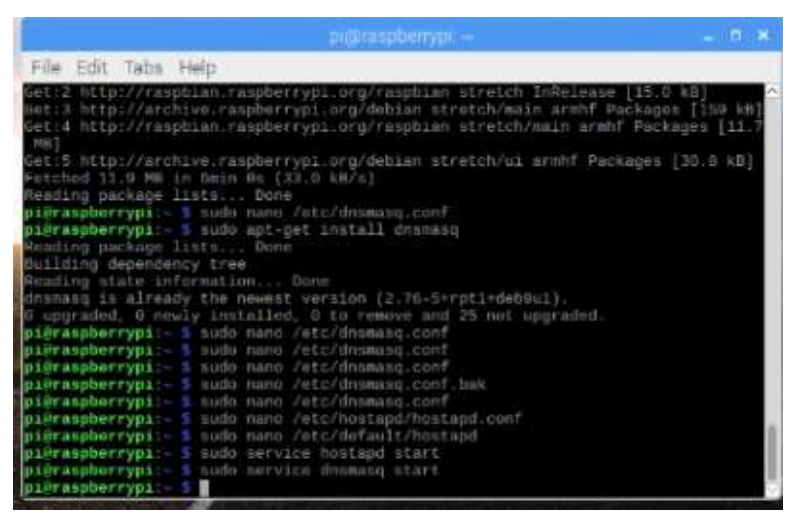

Gbr. 18 Proses restart service hostapd dan dnmasq

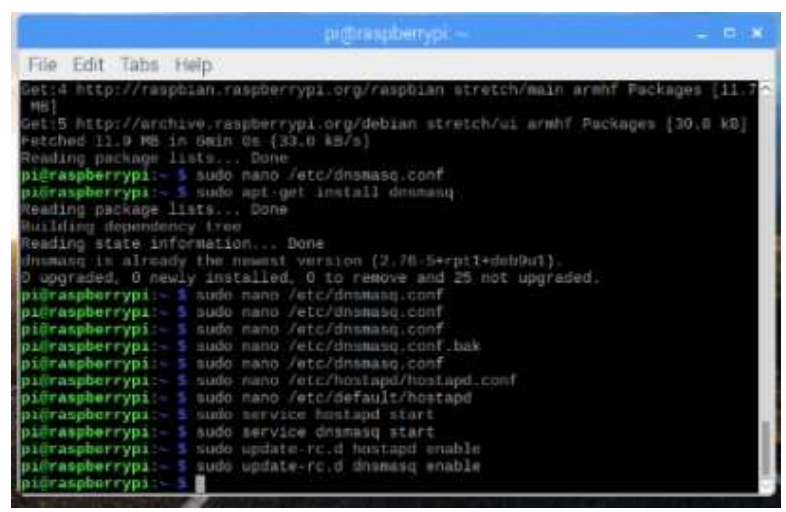

Gbr. 19 Update paket hostapd dan dnsmasq

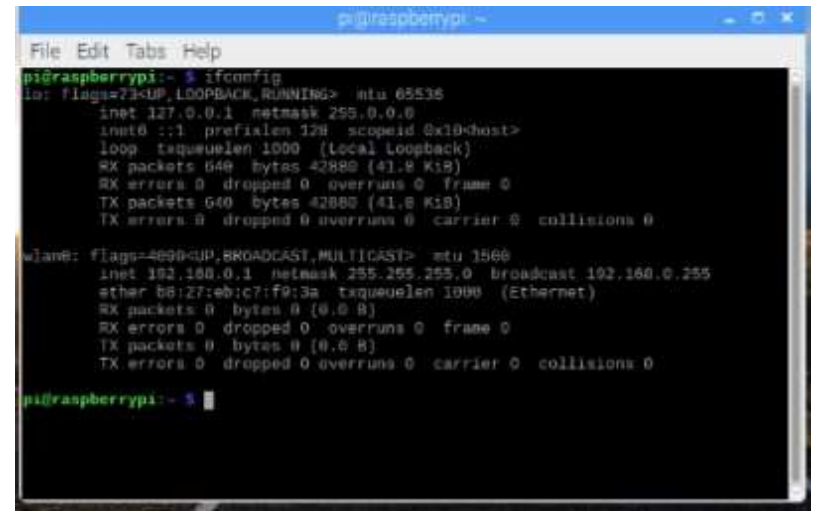

Gbr. 20 Perintah ifconfig untuk melihat hasil akhir konfigurasi 
9) Setelah selesai melakukan konfigurasi baik paket dnsmasq dan paket hostapd serta konfigurasi lain pendukung dalam pengembangan Raspberry Pi menjadi WAP, maka pada hasil berikut ini dilakukan pengaktifan dan update paket hostapd serta dnsmasq.

10) Pada Gbr 20 berikut ini dapat dilihat IP address dan netmask yang telah dikonfigurasikan pada Raspberry Pi:

11) Pengujian dari hasil penelitian yang membuktikan bahwa Raspberry Pi telah menjadi WAP dengan melakukan pemindaian menggunakan smartphone, sperti pada Gbr. 21.

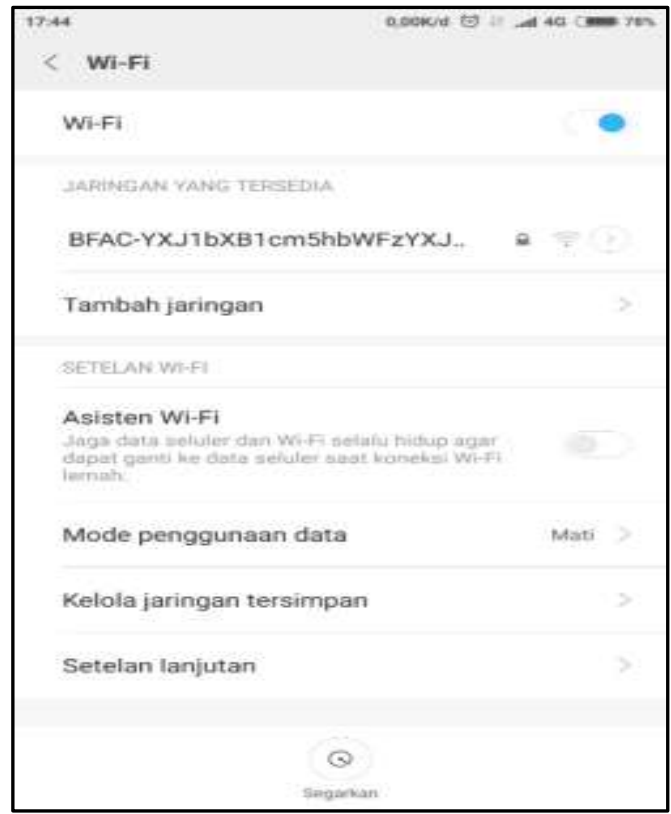

Gbr. 21 Raspberry Pi 3 yang telah terdeteksi sebagai WAP

Hasil dari penelitian yang dilakukan hanya terbatas pada pembuktian bahwa Raspberry Pi 3 dapat diimplementasikan menjadi suatu WAP (Wireless Access Point). Pada penelitian ini, Raspberry Pi 3 menggunakan Sistem Operasi Raspbian untuk dapat menjalankan segala proses kerja dari Raspberry Pi 3 tersebut. Terdapat beberapa konfigurasi yang harus dilakukan agar Raspberry Pi 3 dapat diimplementasikan menjadi WAP, yaitu dengan install paket hostapd dan dnsmasq. Hostapd merupakan paket yang wajib di-install agar Raspberry dapat diimplementasikan menjadi Wireless Router ataupun Wireless Access Point sedangkan dnsmasq dibutuhkan untuk menjalankan DNS dan DHCP server pada Raspberry Pi 3.

Dari penjelasan di atas, dapat diketahui bahwa cukup dengan satu perangkat Raspberry Pi 3 dapat dipergunakan sebagai Wireless Access Point sekaligus juga menjadi server DHCP dan DNS. Dengan pengaturan DHCP pada Raspberry Pi 3 serta pengisian IP address, Raspberry $\mathrm{Pi} 3$ yang bertindak sebagai WAP dapat memberikan IP address secara otomatis kepada user yang terhubung dan pengujian bahwa user dapat memindai Raspberry Pi 3 sebagai WAP dapat dilihat dari hasil penelitian di atas. Pada penelitian ini, telah diujikan kepada 10 user pada STIPER Sriwigama Palembang yang dapat terhubung secara bersamaan, serta untuk selanjutnya Raspberry $\mathrm{Pi} 3$ sebagai WAP ini dapat menampung lebih banyak lagi user akan tetapi akan mempengaruhi kualitas sinyal yang diterima masing-masing user.

\section{KESIMPULAN}

Berdasarkan hasil penelitian, kesimpulan yang diperoleh dari hasil penelitian yang dilakukan yaitu Raspberry Pi 3 merupakan komputer berbentuk mini yang juga memerlukan Sistem Operasi untuk mengoperasikannya, salah satu Sistem Operasinya adalah Rasbian. Selain berfungsi sebagai mini komputer, Raspberry Pi 3 juga dapat dikonfigurasikan serta dimanfaatkan menjadi WAP (Wireless Access Point). WAP yang dibangun dengan mengkonfigurasikan perangkat Raspberry Pi 3 ini dapat membantu dalam hal penyebaran koneksi internet ke setiap sudut STIPER Sriwigama Palembang.

Terdapat beberapa saran yang dapat diberikan baik untuk penggunaan maupun pengembangan hasil penelitian ini, yaitu agar hasil penelitian ini dapat dipergunakan dengan maksimal, ada baiknya untuk dilakukan pelatihan tambahan bagi staf IT untuk memahami tentang karakteristik dan cara kerja Raspberry Pi 3. Untuk peneliti selanjutnya, dapat menerapkan Rancang Bangun WAP (Wireless Access Point) ini terhadap lokasi ataupun instansi lainnya. Selain itu, dapat juga dilakukan pengembangan konfigurasi Raspberry Pi 3 menjadi WAP menggunakan Sistem Operasi lainnya yang lebih lengkap fiturnya.

\section{UCAPAN TERIMA KASIH}

Peneliti mengucapkan terima kasih kepada Ketua, Dosen serta Staf STIPER Sriwigama Palembang yang telah memberikan kesempatan serta dukungan (terutama izin penggunaan perangkat Raspberry $\mathrm{Pi}$ 3) untuk melakukan penelitian serta pengembangan jaringan internet yang telah ada.

\section{DAFTAR PUSTAKA}

[1] I. Sofana, Membangun Jaringan Komputer Mudah Membuat Jaringan Komputer (Wire \& Wireless) Untuk Pengguna Windows dan Linux. Bandung: Informatika, 2013.

[2] R. Novrianda.D, "Rancang Bangun Keamanan Jaringan Wireless pada STIPER Sriwigama Palembang dengan Radius Server," $J$. Maklumatika, vol. 4, no. 1, pp. 19-29, 2017.

[3] and S. W. M. Limantara, Arthur Daniel, Agata Iwan Candra, "Manajemen Data Lalu Lintas Kendaraan Berbasis Sistem Internet Cerdas Ujicoba Implementasi Di Laboratorium Universitas Kadiri,” in Prosiding Semnastek, 2017.

[4] and S. S. Baskoro, Imam Tri, Darjat Darjat, "Perancangan Pengontrolan Nyala Lampu Dan Kipas Angin Pada Sebuah Ruangan Menggunakan Raspberry PI Model B Dengan WEB GUI," TRANSIENT, vol. 3, no. 4, pp. 567-571, 2015.

[5] and G. G. Nataliana, Decy, Iqbal Syamsu, "Sistem Monitoring Parkir Mobil menggunakan Sensor Infrared berbasis RASPBERRY PI," ELKOMIKA J. Tek. Energi Elektr. Tek. Telekomun. Tek. Elektron., vol. 2, no. 1, p. 68, 2014.

[6] and S. W. Richardson, Matt, Getting started with raspberry PI. Sebastopol, California: O’Reilly Media, Inc, 2012.

[7] and M. F. Hidayatullah, Rakhmad Arif, Zamah Sari, "Implementasi Pull Message dengan menggunakan Restful Web Service pada komunikasi Wireless Sensor,” Regist. J. Ilm. Teknol. Sist. Inf., vol. 3, no. 2 , pp. $65-74,2017$.

[8] and I. R. Supriyono, Agus, "Rancang Bangun Sistem Hotspot Menggunakan Captive Portal," JSTIE (Jurnal Sarj. Tek. Inform., vol. 
1, no. 1, pp. 172-180, 2013.

[9] and K. T. Kadir, Abdul, "Analisa Kerja Access Point Jaringan Wireles Pada Universitas Al Asyariah Mandar,” J. Ilmu Komput., vol. 1, no. 1, pp. 01-07, 2017.

[10] E. Fernando, "Automatisasi Smart Home Dengan Raspberry Pi Dan Smartphone Android," in Konferensi Nasional Ilmu Komputer (KONIK) 5, 2014.

[11] and I. R. Nugraha, Azis WW, I. Setiawan, "PEMANFAATAN RASPBERRY PI DAN PERANGKAT LUNAK BEBAS TERBUKA (FOSS) PADA PENDIDIKAN DASAR UNTUK MENGATASI KESENJANGAN DIGITAL," in Prosiding 7.1, 2017.
[12] and S. C. W. Sulenggono, Raka, "Penerapan Sistem Informasi Smart Classroom Berbasis Internet Of Things dengan Raspberry Pi di Jurusan Teknik Informatika Universitas Negeri Surabaya," IT-EDU, vol. 2, no. 2, 2017.

[13] S. Sugiyatno and A. Suroso, "Implementasi Raspberry Pi Sebagai IP Kamera Untuk Pemantauan Studio Bioskop," J. Ilm. Manaj. Inform. dan Komput., vol. 1, no. 1, pp. 5-10, 2017.

[14] I. W. Ardiyasa, "Pemanfaatan Raspberry PI dan Webcam Untuk Layanan Monitoring Ruangan Berbasis Web," in Proceedings Konferensi Nasional Sistem dan Informatika (KNS\&I), 2015. 